\title{
Erratum to: Comparison of selected biochemical parameters between naturally infected and non-infected goats with Anaplasma ovis
}

Mahmood Ahmadi-hamedani • Mahnaz Ahmadi-hamedani • Ezzatollah Fathi · Reza Narenji Sani • Zohreh Khaki

Published online: 20 July 2013

(C) Springer-Verlag London 2013

Erratum to: Comp Clin Pathol

DOI 10.1007/s00580-013-1730-8

The original version of this article inadvertently contained a mistake. Zohreh Khaki is one of the authors but was not included in the original article.

The online version of the original article can be found at http://dx.doi.org/ 10.1007/s00580-013-1730-8.

M. Ahmadi-hamedani $(\bowtie)$

Department of Pathobiology, Faculty of Veterinary Medicine,

Semnan University, Semnan, Iran

e-mail: ahmadi.hamedani@gmail.com

M. Ahmadi-hamedani

Department of Animal Sciences, Faculty of Agriculture,

Ferdowsi University of Mashhad, Mashhad, Iran

E. Fathi

Department of Clinical Sciences, Faculty of Veterinary Medicine,

University of Tabriz, Tabriz, Iran

R. N. Sani

Department of Clinical Sciences, Faculty of Veterinary Medicine,

Semnan University, Semnan, Iran

Z. Khaki

Department of Clinical Sciences, Faculty of Veterinary Medicine,

University of Tehran, Tehran, Iran 